\title{
Can kinematics, file diameter, and PUI influence the intracanal decontamination and apical bacterial extrusion?
}

Maricel Rosario CARDENAS CUELLAR ${ }^{(a)}$ Evelyn Giuliana VELÁSQUEZ-ESPEDILLA ${ }^{(a)}$ Victor Feliz PEDRINHA(a) (ic) Rodrigo Ricci VIVAN(a) (D) Marco Antonio Hungaro DUARTE(a) Flaviana Bombarda de ANDRADE(a)

(a) Universidade de São Paulo - USP, Bauru School of Dentistry, Department of Operative Dentistry, Endodontics and Dental Materials, Bauru, SP, Brazil.

Declaration of Interests: The authors certify that they have no commercial or associative interest that represents a conflict of interest in connection with the manuscript.

Corresponding Author:

Victor Feliz Pedrinha

E-mail: victor_feliz18@hotmail.com

https://doi.org/10.1590/1807-3107bor-2021.vol35.0003
Abstract: The present study investigated the intracanal decontamination and apical extrusion of bacteria and debris from root canals instrumented with rotary and reciprocating systems (ProDesign Logic or ProDesign R), with different file diameters and using conventional syringe irrigation (CSI) or passive ultrasonic irrigation (PUI). Eighty extracted mandibular premolars were contaminated with Enterococcus faecalis and randomly assigned to eight experimental groups according to the root canal instrumentation and irrigation technique employed $(n=10)$ : G1: Prodesign Logic 25.06; G2: Prodesign R 25.06; G3 and G4 were instrumented with the same single-file systems, respectively, using 35.05 diameters and CSI. G5, G6, G7, and G8 were instrumented like the previous groups, but with PUI. Apically extruded debris during instrumentation was collected into pre-weighed microtubes. The weight of the empty microtube was subtracted from the final weight to establish the amount of extruded debris. Bacteria from root canals and extruded debris were collected for a microbiological evaluation of colony forming units (CFU/ $\mathrm{mL}$ ). For statistical analyses, the Mann-Whitney and Kruskal-Wallis followed by the Dunn's tests were used $(a=0.05)$. All instruments caused extrusion of debris. For irrigation techniques, PUI promoted greater debris and bacterial extrusion $(\mathrm{p}<0.05)$. The $\mathrm{CFU} / \mathrm{mL}$ count indicated that the instrumentation of the experimental groups were equally effective in the decontamination of the root canal ( $p>0.05)$. The systems tested (regarding file diameter and kinematics) were associated with similar amounts of apically extruded debris and root canal decontamination. PUI was associated with greater debris and bacterial extrusion.

Keywords: Enterococcus faecalis; Root Canal Irrigants; Root Canal Preparation; Root Canal Therapy; Ultrasonics.

\section{Introduction}

Dentin debris, microorganisms, and irrigating solutions may Submitted: March 18, 2020 Last revision: August 19, 2020 extrude out of the apical foramen to the periradicular tissues during the instrumentation of root canals, regardless of the preparation technique 
and irrigation protocol employed. ${ }^{1,2,3}$ Clinically, these factors promote complications such as postoperative pain, inflammation/infection, and flare-ups, possibly delaying the healing process. ${ }^{4}$ Conventional syringe irrigation (CSI) has been routinely used; nevertheless, there are several limitations related to this technique. ${ }^{5}$ Aiming for better antisepsis of the root canal system, agitation of the irrigation solution was performed by passive ultrasonic irrigation (PUI), wherein an activation of an ultrasonic tip inside the root canal along the working length (WL) is performed and moved passively in up-and-down motions, ${ }^{6}$ helping to remove debris and remnants of the pulp tissue. ${ }^{6,7}$ However, further studies must be carried out to fully clarify the issue of debris extrusion performed by PUI activation. In addition, the variety of file systems and irrigation protocols requires as many comparisons as possible to provide consistent evidence.

Several single-file nickel-titanium (NiTi) systems with different designs, alloy treatments and kinematics have been introduced in Endodontics, aiming for benefits in relation to the effectiveness and safety of the endodontic instruments. ${ }^{8,9}$ ProDesign Logic and ProDesign $\mathrm{R}$ are single-file mechanical systems (Easy Equipamentos Odontológicos, Belo Horizonte, Brazil) manufactured in control memory (CM) wire alloy. ${ }^{9,10}$ The former performs continuous rotation or reciprocating motion and is available in four different tip sizes/tapers: 25.06, 30.05, 35.05, and 40.05 to be selected according to the initial diameter of the canals. The latter exclusively reciprocates with a variable helical angle and a counterclockwise cut. It is available in two instruments with different tip sizes/tapers: 25.06 and $35.05 .{ }^{10}$ Both systems presented S-shaped cross-sections with two cutting edges and inactive points. ${ }^{9,10}$

Information regarding disinfection and apical debris extrusion is available for most systems. ${ }^{11}$ Therefore, the present in vitro study aimed to comparatively evaluate the ProDesign Logic and ProDesign R files in both kinematics - rotation and reciprocating - and two file diameters in relation to apically extruded debris and also bacteria, using CSI or PUI. In addition, we evaluated which of them promoted better intracanal decontamination.

\section{Methodology}

\section{Specimen selection}

The present study was approved by the local Research Ethics Committee. Only teeth with single root canals and an initial apical diameter corresponding to a size $15 \mathrm{~K}$-file were selected. Computerized microtomographs were performed aiming at obtaining specimens with similar characteristics. This selection process resulted in eighty extracted human mandibular premolars that met the above-mentioned criteria. Teeth that presented immature apexes, root caries, root fractures, cracks, lacerations, sharp curvatures, canal calcifications, or endodontic treatment were excluded; these features were identified with the aid of a stereomicroscope (SMX800, Nikon Co., NY, USA) under 20X magnification. After immersion in $1 \%$ sodium hypochlorite $(\mathrm{NaOCl})$, endodontic access cavities were prepared (EndoAccess Bur; Dentsply Maillefer, Ballaigues, Switzerland) with a high-speed handpiece. The pulp chambers were accessed, and the crown was maintained to create a reservoir for infection of root canals with a suspension of Enterococcus faecalis according to a previously described methodology. ${ }^{12}$

The canals were explored with \#10 and \#15 K files (Dentsply Maillefer, Ballaigues, Switzerland) and instrumented to standardize the initial diameters with a 25.01 Prodesign Logic file (Easy Equipamentos Odontológicos, $\mathrm{BH}$, Brazil) $1 \mathrm{~mm}$ from the root apex and irrigated with $5 \mathrm{~mL}$ of saline solution. The lengths of specimens were standardized at 16 $\mathrm{mm}$. Next, three ultrasonic baths were performed with $1 \% \mathrm{NaOCl}, 17 \%$ ethylenediaminetetraacetic acid (EDTA), and phosphate-buffered saline (PBS) solution, respectively, for $10 \mathrm{~min}$ each, followed by distilled water to eliminate EDTA and $\mathrm{NaOCl}$ residues and open up the dentinal tubules according to a previously described protocol. ${ }^{6,13}$ The specimens were sterilized individually in microtubes with distilled water in an autoclave (Cristófoli, Campo Mourão, Brazil) at $121^{\circ} \mathrm{C}$ for $24 \mathrm{~min}$, inserted in Brain Heart Infusion (BHI) sterile culture media (Difco, Detroit, USA), and submitted to an ultrasonic bath 
for $10 \mathrm{~min}$ for maximum penetration of the culture broth into the dentinal tubules.

\section{Contamination of the specimens}

The bacterial strain Enterococcus faecalis ATCC 29212 (American Type Culture Collection) was reactivated. The purity was confirmed by colonial morphology and Gram staining (Oxoid, Basingstone, UK). The culture was adjusted according to the McFarland standard \#1 (3×10 CFU/mL) using an SF325NM spectrophotometer (Bel Photonics do Brasil Ltda., Osasco, Brazil), and the suspension was kept at $37^{\circ} \mathrm{C}$ for $7 \mathrm{~h}$ to reach exponential bacterial growth. The contamination of the specimens lasted for 5 days at $37^{\circ} \mathrm{C}$, according to the centrifugation protocol described by Andrade et al. ${ }^{14}$ and Ma et al. ${ }^{15}$ On the fifth day, the samples were removed from the microtubes and inserted in a sterilized metal device. All experiments were performed under aseptic conditions inside a laminar flow hood.

\section{Root canals instrumentation}

A single operator performed the instrumentation of the root canals. For the experimental procedures of the present study, we used a previous experimental model closed system modified with sterilized microtubes $(2 \mathrm{~mL}) .{ }^{12}$ The apical part of the root was suspended within the microtube, which acted as a collecting container for apical material extruding through the foramen of the root. The files were activated in an Easy Dental electric motor (Easy Equipamentos Odontológicos, Belo Horizonte, Brazil) at $950 \mathrm{rpm}$ and $4.0 \mathrm{Ncm}$ and inserted into the canals with vertical movements until the WL. The ProDesign Logic was used in continuous rotation and the ProDesign $R$ in reciprocating motion. After instrumentation, the files were sterilized for another use. Each instrument was only used to prepare four canals before discarding. The specimens were randomly assigned to eight experimental groups $(n=10)$, according to the single-file and irrigation technique. For the following groups, the CSI technique was performed: G1 - ProDesign Logic 25.06; G2 - ProDesign R 25.06; G3 - ProDesign Logic 35.05 and G4 - ProDesign R 35.05. The next groups were PUI-activated: G5 - ProDesign Logic 25.06; G6
- ProDesign R 25.06; G7 - ProDesign Logic 35.05; and G8 - ProDesign R 35.05.

The root canals were irrigated using 30 -gauge Navitip needles (Ultradent Products Inc., South Jordan, EUA) inserted to $3 \mathrm{~mm}$ short of the WL during instrumentation using a total of $7 \mathrm{~mL}$ of distilled water. The irrigant was aspirated simulating a clinical situation with a portable surgical aspirator (Nevoni - 5005BRST, Barueri, Brazil). For PUI, a piezoelectric device was used at a frequency of $30000 \mathrm{~Hz}$ (Emissonic MMO Jardim São Carlos, São Carlos, Brazil), together with an Irrisonic E1 tip (Helse, Santa Rosa de Viterbo, Brazil) inserted 3 $\mathrm{mm}$ short of the WL, 3 times for 20 sec each, totaling $1 \mathrm{~min}$ of agitation. The procedure was conducted with vertical movements in the buccal-lingual and mesial-distal directions. Additionally, in the PUI groups, $7 \mathrm{~mL}$ of distilled water was used.

\section{Microbiological samples of root canals}

Microbiological samples were obtained using two \#20 absorbent paper points (Dentsply Maillefer, Ballaigues, Switzerland) before and after instrumentation. The points were inserted into the canals for $1 \mathrm{~min}$ and then transferred to microtubes containing $1 \mathrm{~mL}$ of BHI (Brain Heart Infusion) broth. All samples were collected with $20 \mu \mathrm{L}$ of sterile saline inside the canals to standardize the volume absorbed by the paper points. The microtubes were vortexed for $1 \mathrm{~min}$, and $100 \mu \mathrm{L}$ aliquots were transferred to others microtubes with $900 \mu \mathrm{L}$ of BHI, until a dilution of $10^{-2}$ was reached. One hundred microliters of the dilutions were plated on Petri dishes with BHI agar. The Petri dishes were stored at $37^{\circ} \mathrm{C}$ for $48 \mathrm{~h}$ for subsequent $\mathrm{CFU} / \mathrm{mL}$ count. The first sample collected for each specimen was used as a positive control, confirming the standardization of the initial contamination.

\section{Extrusion of debris and bacteria}

The microtubes $(2 \mathrm{~mL})$ were initially weighed on a $0.0001 \mathrm{~g}$ precision analytical digital weight scale (Adventurer Ohaus AR2140 class I, São Bernardo do Campo, Brazil). Three consecutive measurements were obtained for each microtube. The average value was recorded and then the microtube was 
attached under each specimen to collect the extruded debris during the chemomechanical preparation. Subsequently, three absorbent paper points (\#20) were inserted into the microtubes with the irrigant and the contaminated debris and this set were stirred in a vortex (Vortex-mix VX200, Edison, USA) for $1 \mathrm{~min}$. This procedure was performed with the aim to standardize the sample collections, since each paper point could absorb a bacterial quantity as representative as possible for each specimen and differing from methods in which not all the contaminated material could be collected. Next, paper points were transferred to a microtube with 1 $\mathrm{mL}$ of $\mathrm{BHI}$ broth. From this content, dilutions were made in the same way as the root canal collections and seeded on BHI agar plates.

The microtubes containing the debris were centrifuged at $11000 \mathrm{rpm}$ and $25{ }^{\circ} \mathrm{C}$ for $2 \mathrm{~min}$ (Eppendorf TM 5424 microcentrifuges, Hamburg, Germany) to obtain a concentrate of the extruded debris at the bottom of microtubes to perform the weighing again. The centrifugation procedure could avoid the presence of suspended debris and permit the reduction of drying time. The supernatant was partially removed carefully with a pipette and the microtubes were allowed to dry in the oven at $37^{\circ} \mathrm{C}$ for $48 \mathrm{~h}$. The microtubes were again weighed three times to obtain the average weight. The dry weight of the extruded debris was calculated by subtracting the initial weight of the empty tube from the weight of the microtube. ${ }^{16}$

\section{Control group}

Five additional mandibular pre-molars, which had been previously infected, were used as positive controls $\left(\mathrm{C}^{+}\right)$to confirm intratubular contamination, and two additional specimens were used as negative controls $\left(\mathrm{C}^{-}\right)$, wherein the teeth were not infected to confirm sterility. The specimens were sectioned longitudinally in an Isomet machine (Buehler Ltd, Lake Bluff, IL, USA) with a diamond disk under constant irrigation with sterile saline solution. The smear layer resulting from the cut was removed by immersion in 17\% EDTA for $5 \mathrm{~min}$ and washing with saline solution, as previously reported in the literature. ${ }^{13,17,18}$ According to these reported studies, the EDTA wash after the cut showed no effect on bacterial viability.

Root halves were stained with $30 \mu \mathrm{L}$ of dye from a LIVE/DEAD® BacLight bacterial viability kit (Invitrogen Molecular Probes, Eugene, OR, USA). This kit contains the green dye SYTO $9 \AA$, which stains viable bacteria, and the red dye propidium iodide, which stains dead bacteria. After $20 \mathrm{~min}$ of contact with the dye, each sample was gently washed with PBS to remove the residual dye. The specimens were placed on a glass slide with immersion oil and observed using a Leica TCS-SPE confocal microscope (Leica Microsystems $\mathrm{GmbH}$, Mannheim, Germany) at $40 x$ magnification.

\section{Statistical analyses}

All data were initially analyzed using the Shapiro-Wilk test to verify the normality. The Kruskal-Wallis and Dunn's post-hoc tests were performed to analyze the data of extruded debris and bacteria. The CFU counts were log-transformed before performing the statistical tests. The intracanal efficacy against $E$. faecalis using the instrumentation systems was expressed as a percentage of reduction and calculated for each group as follows: (CFUs pre-instrumentation/CFUs post-instrumentation $\mathrm{x}$ 100). $\cdot{ }^{19}$ For the $\mathrm{CFU} / \mathrm{mL}$ count, intergroup comparisons were performed by the Kruskal-Wallis followed by the Dunn's tests. The Mann-Whitney test was used for comparison between the PUI or CSI and for each group comparison regarding contamination before and after instrumentation. The GraphPad Prism 8.0 software (GraphPad San Diego, USA) was the analytical tool $(\alpha=0.05)$.

\section{Results}

All the instruments tested caused extrusion of debris through the apical foramen. When analyzing irrigation techniques, we found that CSI extruded less debris and bacteria in relation to PUI activation $(p<0.05)$ (Table 1) (Figure 1). No bacterial growth was observed in the negative control group. All positive controls demonstrated a higher proportion of viable bacteria inside the dentinal tubules, confirming the efficacy of the contamination protocol (Figure 2). The 
$\mathrm{CFU} / \mathrm{mL}$ analyses showed that both instrumentation systems with different file diameters, kinematics and irrigation type reduced the bacterial amount $(\mathrm{p}>0.05)$ inside the main root canals (Table 2). There are no differences between the groups of instrumentation for bacterial extrusion regarding file diameter, kinematics, and irrigation type performed when comparing all groups $(\mathrm{p}>0.05)$ (Table 3$)$.

Table 1. The median $(\mathrm{m})$ and minimum and maximum (min-max) values of apically extruded debris by the tested nickel-titanium files in the experimental groups (grams).

\begin{tabular}{lll}
\hline Groups & $\mathrm{m}$ & min-max \\
\hline Conventional syringe irrigation & & \\
ProDesign Logic 25.06 & $0.20^{\mathrm{a}}$ & $0.1-0.6$ \\
ProDesign R 25.06 & $0.20^{\mathrm{a}}$ & $0.1-2.1$ \\
ProDesign Logic 35.05 & $0.30^{\mathrm{ab}}$ & $0.1-1.6$ \\
ProDesign R 35.05 & $0.30^{\mathrm{ab}}$ & $0.1-1.4$ \\
Passive ultrasonic irrigation & & \\
ProDesign Logic 25.06 & $0.80^{\mathrm{abcd}}$ & $0.4-2.3$ \\
ProDesign R 25.06 & $1.10^{\mathrm{bcd}}$ & $0.6-1.4$ \\
ProDesign Logic 35.05 & $1.20^{\mathrm{cd}}$ & $0.7-2.9$ \\
ProDesign R 35.05 & $1.30^{\mathrm{d}}$ & $0.6-2.9$ \\
\hline
\end{tabular}

Different superscript letters indicate a significant difference between groups $(p<0.05)$.

\section{Discussion}

The ProDesign Logic and ProDesign R singlefile mechanical systems were chosen because there is a lack of information regarding their effects for decontamination of root canals and apical extrusion of debris and bacteria when associated with two commonly performed irrigation techniques. In view of the results, differences among the groups were statistically significant with respect to the amount of apically extruded debris and bacteria.

A reduction in debris extrusion is desirable to help reduce postoperative pain after root canal treatment. ${ }^{4}$ The results indicated that apical extrusion occurred in all the single-file systems tested with the two irrigation techniques evaluated. However, PUI activation produced more debris extrusion than CSI. These findings are confirmed by previous studies. ${ }^{3,20}$ Karatas et al evaluated the effect of the Vibringe, EndoVac, non-activated self-adjusting file system (SAF), PUI and CSI techniques for the amount of extruded debris. ${ }^{3}$ SAF showed the best results compared with the other groups and PUI showed higher extrusion values. Therefore, in the present study, the ultrasonic agitation of distilled water in the apical third of the root canal may force this solution towards the apical foramen and thus

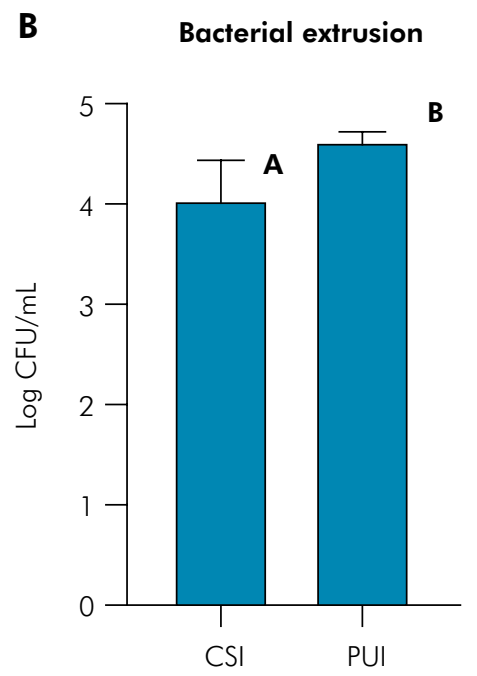

Figure 1. CSI, Conventional Syringe Irrigation; PUI, Passive Ultrasonic Irrigation. Different superscript letters indicate a significant difference between groups by the Mann Whitney test $(p<0.05)$. 
increase debris extrusion, which could consequently cause the largest extrusion of bacteria.

The agitation of solution by PUI is important and strongly recommended to improve the antisepsis of the root canal system and eliminate microorganisms,

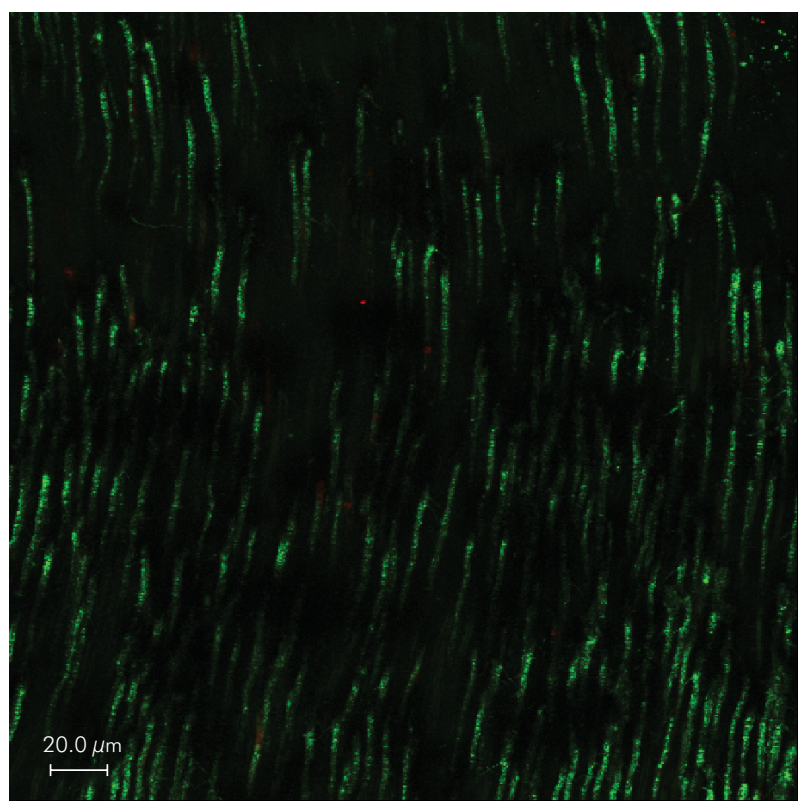

Figure 2. Confocal laser scanning microscopy image of the positive control group after intratubular contamination protocol. Viable bacteria are indicated in green, and nonviable bacteria are indicated in red. Magnification: $40 \mathrm{x}$. including areas of difficult access such as the isthmus, where Enterococcus faecalis and other species can penetrate and remain viable as in persistent infections. ${ }^{4,5,21,22}$ It should, therefore, be considered that there is a possible amount of debris produced during the treatments. PUI can remove debris from the dentinal walls of the root canal, but without due care, can be extruded through the foramen and can cause tissue inflammation even though painful symptoms may not be present.

Regarding single-files, the ability to effectively remove dentin depends on the number of edges, cross-sectional design, helical angle, tip size, core and surface treatment. ${ }^{8}$ In the present study, no significant differences were found between the kinematics and file diameter of the systems. Previous studies show several results when evaluating mechanical systems with different manufacturing characteristics. ${ }^{7,23,24}$ Our study investigated files with a cylindrical core and a S-shaped cross section of the same manufacturer, which does not allow a large cut of dentine, thus, the design of these systems possibly contributed to our results.

Previous studies are controversial in terms of the correlation between the amount of apically extruded debris and the file tip sizes. The importance of apical preparation has been discussed, there being

Table 2. Reduction in percentage (\%) of Enterococcus faecalis inside root canals with single-file systems using distilled water ( $\mathrm{n}=10$ group).

\begin{tabular}{|c|c|c|c|}
\hline \multirow{3}{*}{ Groups } & Before instrumentation & After instrumentation & Reduction (\%) \\
\hline & (Log 10 CFU/mL) & (Log10 CFU/mL) & m (min-max) \\
\hline & $m(\min -\max )$ & m (min-max) & \\
\hline \multicolumn{4}{|c|}{ Conventional syringe ilrrigation } \\
\hline ProDesign Logic 25.06 & $6.16(6.11 \pm 6.20)$ & $4.54(4.08 \pm 4.86)$ & $72.85(66.2 \pm 79.0)^{*}$ \\
\hline ProDesign R 25.06 & $6.17(6.11 \pm 6.21)$ & $4.05(3.42 \pm 4.81)$ & $65.83(55.5 \pm 78.0)^{*}$ \\
\hline ProDesign Logic 35.05 & $6.17(6.11 \pm 6.21)$ & $4.51(4.28 \pm 4.73)$ & $72.76(69.5 \pm 76.7)^{*}$ \\
\hline ProDesign R 35.05 & $6.19(6.12 \pm 6.22)$ & $4.70(4.26 \pm 5.00)$ & $75.62(69.3 \pm 80.6)^{*}$ \\
\hline \multicolumn{4}{|l|}{ Passive ultrasonic irrigation } \\
\hline ProDesign Logic 25.06 & $6.18(6.10 \pm 6.22)$ & $5.11(4.67 \pm 5.22)$ & $82.66(75.7 \pm 84.9)^{*}$ \\
\hline ProDesign R 25.06 & $6.18(6.14 \pm 6.21)$ & $4.11(4.16 \pm 4.89)$ & $73.13(67.2 \pm 79.3)^{*}$ \\
\hline ProDesign Logic 35.05 & $6.18(6.17 \pm 6.22)$ & $4.63(4.17 \pm 4.83)$ & $75.38(67.3 \pm 78.0)^{*}$ \\
\hline ProDesign R 35.05 & $6.16(6.12 \pm 6.20)$ & $4.61(4.22 \pm 4.96)$ & $74.62(68.5 \pm 80.5)^{*}$ \\
\hline
\end{tabular}

M: median; min: minimum; max: maximum; Comparison by Kruskal-Wallis and Dunn's post hoc tests. *No statistically significant differences. 
Table 3. Data of Apical Extrusion of Enterococcus faecalis after Mechanical Preparation with Single-file Systems ( $\mathrm{n}=10$ group).

\begin{tabular}{|c|c|}
\hline \multirow{3}{*}{ Groups } & After instrumentation \\
\hline & (Log10 CFU/mL) \\
\hline & $\mathrm{m}(\min -\max )$ \\
\hline \multicolumn{2}{|c|}{ Conventional syringe irrigation } \\
\hline ProDesign Logic 25.06 & $4.02(3.74 \pm 4.56)^{*}$ \\
\hline ProDesign R 25.06 & $4.05(2.83 \pm 5.00)^{*}$ \\
\hline ProDesign Logic 35.05 & $4.12(2.14 \pm 4.90)^{*}$ \\
\hline ProDesign R 35.05 & $4.11(3.62 \pm 4.50)^{*}$ \\
\hline \multicolumn{2}{|c|}{ Passive ultrasonic irrigation } \\
\hline ProDesign Logic 25.06 & $4.80(4.49 \pm 5.02)^{*}$ \\
\hline ProDesign R 25.06 & $4.39(4.14 \pm 4.92)^{*}$ \\
\hline ProDesign Logic 35.05 & $4.61(4.37 \pm 5.00)^{*}$ \\
\hline ProDesign R 35.05 & $4.59(3.95 \pm 4.85)^{*}$ \\
\hline
\end{tabular}

no agreement on the choice of instruments and which are the most suitable. Predetermined sizes beyond 30 or 35 have been suggested, ${ }^{25}$ as well as increased enlargements by three instruments than the anatomical diameter. ${ }^{26}$ Other authors have suggested that the taper is more important than the tip size. ${ }^{27}$ In the present study, no consistent correlation was found between the amount of extruded debris and the tip size of single-files.

Another way of evaluating the antisepsis capacity of the root canal system is through microbiological collection before and after instrumentation. The present study showed a reduction in the number of $\mathrm{CFU} / \mathrm{mL}$ amongst the experimental groups in corroboration with other studies. ${ }^{28,29}$ Considering that the amount of bacteria extruded is the pathologic component of debris, ${ }^{30}$ E. faecalis, a commonly found Gram-positive facultative anaerobe in failed endodontically treated root canals was chosen for contamination. ${ }^{25}$ To evaluate the amount of bacterial extrusion, a five-day protocol for in vitro intratubular dentinal bacterial contamination was chosen ${ }^{13}$ because bacterial formation as a mature biofilm is a complex structure and is much more difficult to eliminate. ${ }^{12,31}$ To minimize considerable variations between the different groups and to produce a reliable and comparable anatomic baseline, single-rooted, single canal, mandibular pre-molars instrumented to standardize the initial diameters with a 25.01 Prodesign Logic file (Easy Equipamentos Odontológicos, Belo Horizontes, Brazil) were selected for the present study.

It is important to point out that caution is required to infer clinical significance regarding the present results due to the in vitro nature of the present study. Distilled water was used as an irrigant because it is innocuous since our objective was to evaluate the bacterial extrusion promoted by instrumentation techniques and not the antimicrobial efficacy of the irrigant. The extrusion of a solution with antimicrobial effect, such as $\mathrm{NaOCl}$, could cause false negative results, preventing the detection and differentiation of the experimental groups. In addition, had we used antimicrobial agents, there would probably be few bacteria, almost none, making it hard to compare the instrumentation techniques. Vasconcelos et al. ${ }^{6}$ also used distilled water as an irrigation solution showing that PUI-agitation promoted a significant bacterial reduction in CFUs/mL inside root canals. Other studies also microbiologically evaluated extrusion using an innocuous solution. $13,30,32$ This approach is commonly performed in studies to facilitate quantification of apically extruded bacteria, avoid their destruction. 12,30,33

To circumvent the limitations of debris extrusion methods, no device was used that could simulate the periodontal ligament. Although periapical tissues may act as a natural barrier to prevent debris/ bacterial extrusion, studies reported that extrusion accidents generally occur in teeth with periapical pathology that lack such barrier. ${ }^{34}$ Furthermore, apically extruded bacteria are related to acute inflammatory responses of the periradicular tissues and the intensity of these inflammatory responses is not only related to the number of bacteria (quantitative factor), but also to bacteria virulence (qualitative factor). ${ }^{12,35}$ Thus, it is necessary to emphasize that the interplay between the number and bacteria virulence must be considered.

Any system used causes debris extrusion through the apical foramen, indicating that the use of ultrasound is still important for its ability to remove debris and pulp remnants in hard to reach areas such as the 
isthmus. As a result, it is possible to suggest the use of ultrasonic agitation only after the chemical-mechanical decontamination procedures have been performed, thus avoiding a possible extrusion of contaminated debris, as well as the ultrasonic insert should be at $3 \mathrm{~mm}$ or more short of the WL.

The technique of irrigation "apical negative pressure" is suggested as an alternative option to avoid extrusions and showed good results for the reduction of the volume of the irrigation solution released via the apical foramen, ${ }^{3,32}$ however, there is no guarantee of a decrease in the extrusion. Methodologies evaluating these variations should be the subject of future studies. In the present study, the aspiration of solution was performed simulating a clinical situation with the intention of reducing the excess of debris inside the root canals. ${ }^{33}$

Due to the in vitro nature of this experiment, the results obtained should be analyzed with caution when extrapolating them to clinical conditions. The paper points can collect only bacteria from the main root canals. In addition, some E. faecalis cells in biofilms can enter in a stationary phase, which makes them undetectable with conventional culture methods, thus, bacteria may remain deep inside the dentinal tubules. The validation of this test can be considered since the objective was only to verify if debris were extruded, as well as bacteria, and if these events were similar for experimental single-file systems, file diameters, and irrigation techniques. Thus, to the best of our knowledge, this is the first study to evaluate contaminated debris extrusion after PUI agitation of irrigating solution.

\section{Conclusion}

There was a similar decontamination of the root canal performed by single-file systems. The same amount of extruded and contaminated debris was also found for the instrumentation techniques investigated, regarding different file diameters and kinematics. Passive ultrasonic irrigation promoted a greater extrusion of contaminated dentinal debris.

\section{Acknowledgments}

The authors deny any conflicts of interest relevant to this study. The authors thank Capes (Coordination of Higher Education and Post-Graduation), CNPq (National Council of Scientific and Technological Development) and Fapesp (São Paulo Research Foundation - process number 2010/20186-3) for supporting this study.

\section{References}

1. Seltzer S, Naidorf IJ. Flare-ups in endodontics: I. Etiological factors. J Endod. 1985 Nov;11(11):472-8. https://doi.org/10.1016/S0099-2399(85)80220-X

2. Uslu G, Özyürek T, Yılmaz K, Gündoğar M, Plotino G. Apically extruded debris during root canal instrumentation with Reciproc Blue, HyFlex EDM, and XP-endo Shaper Nickel-titanium Files. J Endod. 2018 May;44(5):856-9. https://doi.org/10.1016/i.joen.2018.01.018

3. Karatas E, Ozsu D, Arslan H, Erdogan AS. Comparison of the effect of nonactivated self-adjusting file system, Vibringe, EndoVac, ultrasonic and needle irrigation on apical extrusion of debris. Int Endod J. 2015 Apr;48(4):317-22. https://doi.org/10.1111/iej.12317

4. Siqueira JF Jr. Microbial causes of endodontic flare-ups. Int Endod J. 2003 Jul;36(7):453-63. https://doi.org/10.1046/j.1365-2591.2003.00671.x

5. van der Sluis LW, Versluis M, Wu MK, Wesselink PR. Passive ultrasonic irrigation of the root canal: a review of the literature. Int Endod J. 2007 Jun;40(6):415-26. https://doi.org/10.1111/j.1365-2591.2007.01243.x

6. Vasconcelos LR, Midena RZ, Minotti PG, Pereira TC, Duarte MA, Andrade FB. Effect of ultrasound streaming on the disinfection of flattened root canals prepared by rotary and reciprocating systems. J Appl Oral Sci. 2017 Sep-Oct;25(5):477-82. https://doi.org/10.1590/1678-7757-2016-0358

7. Di Fiore PM, Genov KA, Komaroff E, Li Y, Lin L. Nickel-titanium rotary instrument fracture: a clinical practice assessment. Int Endod J. 2006 Sep;39(9):700-8. https://doi.org/10.1111/j.1365-2591.2006.01137.x

8. Plotino G, Ahmed HM, Grande NM, Cohen S, Bukiet F. Current assessment of reciprocation in endodontic preparation: a comprehensive review. part II: Properties and Effectiveness. J Endod. 2015 Dec;41(12):1939-50. https://doi.org/10.1016/i.joen.2015.08.018 
9. Alcalde MP, Duarte MA, Bramante CM, Tanomaru-Filho M, Vasconcelos BC, Só MV, et al. Torsional fatigue resistance of pathfinding instruments manufactured from several nickel-titanium alloys. Int Endod J. 2018 Jun;51(6):697-704. https://doi.org/10.1111/iej.12879

10. Duque JA, Vivan RR, Duarte MA, Alcalde MP, Cruz VM, Borges MM, et al. Effect of larger apical size on the quality of preparation in curved canals using reciprocating instruments with different heat thermal treatments. Int Endod J. 2019 Nov;52(11):1652-9. https://doi.org/10.1111/iej.13165

11. Gu LS, Kim JR, Ling J, Choi KK, Pashley DH, Tay FR. Review of contemporary irrigant agitation techniques and devices. J Endod. 2009 Jun;35(6):791-804. https://doi.org/10.1016/i.joen.2009.03.010

12. Tinoco JM, De-Deus G, Tinoco EM, Saavedra F, Fidel RA, Sassone LM. Apical extrusion of bacteria when using reciprocating single-file and rotary multifile instrumentation systems. Int Endod J. 2014 Jun;47(6):560-6. https://doi.org/10.1111/iej.12187

13. Marinho AC, Martinho FC, Gonçalves LM, Rabang HR, Gomes BP. Does the Reciproc file remove root canal bacteria and endotoxins as effectively as multifile rotary systems? Int Endod J. 2015 Jun;48(6):542-8. https://doi.org/10.1111/iej.12346

14. Andrade FB, Arias MP, Maliza AG, Duarte MA, Graeff MS, Amoroso-Silva PA, et al. A new improved protocol for in vitro intratubular dentinal bacterial contamination for antimicrobial endodontic tests: standardization and validation by confocal laser scanning microscopy. J Appl Oral Sci. 2015 Nov-Dec;23(6):591-8. https://doi.org/10.1590/1678-775720140261

15. Ma J, Wang Z, Shen Y, Haapasalo M. A new noninvasive model to study the effectiveness of dentin disinfection by using confocal laser scanning microscopy. J Endod. 2011 Oct;37(10):1380-5. https://doi.org/10.1016/i.joen.2011.06.018

16. Gunes B, Yesildal Yeter K. Effects of different glide path files on apical debris extrusion in curved root canals. J Endod. 2018 Jul;44(7):1191-4. https://doi.org/10.1016/i.joen.2018.04.012

17. Pereira TC, da Silva Munhoz Vasconcelos LR, Graeff MS, Ribeiro MC, Duarte MA, Andrade FB. Intratubular decontamination ability and physicochemical properties of calcium hydroxide pastes. Clin Oral Investig. 2019 Mar;23(3):1253-62. https://doi.org/10.1007/s00784-018-2549-0

18. Giardino L, Del Fabbro M, Cesario F, Fernandes FS, Andrade FB. Antimicrobial effectiveness of combinations of oxidant and chelating agents in infected dentine: an ex vivo confocal laser scanning microscopy study. Int Endod J. 2018 Apr;51(4):448-56. https://doi.org/10.1111/iej.12863

19. Ferrer-Luque CM, Bejarano I, Ruiz-Linares M, Baca P. Reduction in Enteroccocus faecalis counts - a comparison between rotary and reciprocating systems. Int Endod J. 2014 Apr;47(4):380-6. https://doi.org/10.1111/iej.12158

20. Desai P, Himel V. Comparative safety of various intracanal irrigation systems. J Endod. 2009 Apr;35(4):545-9. https://doi.org/10.1016/j.joen.2009.01.011

21. Zehnder M, Guggenheim B. The mysterious appearance of enterococci in filled root canals. Int Endod J. 2009 Apr;42(4):277-87. https://doi.org/10.1111/j.1365-2591.2008.01537.x

22. Sabins RA, Johnson JD, Hellstein JW. A comparison of the cleaning efficacy of short-term sonic and ultrasonic passive irrigation after hand instrumentation in molar root canals. J Endod. 2003 Oct;29(10):674-8. https://doi.org/10.1097/00004770-200310000-00016

23. Alves FR, Paiva PL, Marceliano-Alves MF, Cabreira LJ, Lima KC, Siqueira Junior JF, et al. Bacteria and hard tissue debris extrusion and intracanal bacterial reduction promoted by XP-endo shaper and reciproc instruments. J Endod. 2018 Jul;44(7):1173-8. https://doi.org/10.1016/j.joen.2018.04.007

24. Silva EJ, Carapiá MF, Lopes RM, Belladonna FG, Senna PM, Souza EM, et al. Comparison of apically extruded debris after large apical preparations by full-sequence rotary and single-file reciprocating systems. Int Endod J. 2016 Jul;49(7):700-5. https://doi.org/10.1111/iej.12503

25. Siqueira JF Jr, Rôças IN, Riche FN, Provenzano JC. Clinical outcome of the endodontic treatment of teeth with apical periodontitis using an antimicrobial protocol. Oral Surg Oral Med Oral Pathol Oral Radiol Endod. 2008 Nov; 106(5):757-62 https://doi.org/10.1016/i.tripleo.2008.06.007

26. Souza RA, Dantas JC, Brandão PM, Colombo S, Lago M, Duarte MA. Apical third enlargement of the root canal and its relationship with the repair of periapical lesions. Eur J Dent. 2012 Oct;6(4):385-8. https://doi.org/10.1055/s-0039-1698976

27. Albrecht LJ, Baumgartner JC, Marshall JG. Evaluation of apical debris removal using various sizes and tapers of ProFile GT files. J Endod. 2004 Jun;30(6):425-8. https://doi.org/10.1097/00004770-200406000-00012

28. Kuştarci A, Akpinar KE, Sümer Z, Er K, Bek B. Apical extrusion of intracanal bacteria following use of various instrumentation techniques. Int Endod J. 2008 Dec;41(12):1066-71. https://doi.org/10.1111/j.1365-2591.2008.01470.x

29. Machado ME, Nabeshima CK, Leonardo MF, Reis FA, Britto ML, Cai S. Influence of reciprocating single-file and rotary instrumentation on bacterial reduction on infected root canals. Int Endod J. 2013 Nov;46(11):1083-7. https://doi.org/10.1111/iej.12108

30. Aksel H, Küçükkaya Eren S, Çakar A, Serper A, Özkuyumcu C, Azim AA. Effect of instrumentation techniques and preparation taper on apical extrusion of bacteria. J Endod. 2017 Jun;43(6):1008-10. https://doi.org/10.1016/i.joen.2017.01.014

31. Shen Y, Stojicic S, Haapasalo M. Antimicrobial efficacy of chlorhexidine against bacteria in biofilms at different stages of development. J Endod. 2011 May;37(5):657-61. https://doi.org/10.1016/i.joen.2011.02.007 
- Can kinematics, file diameter, and PUI influence the intracanal decontamination and apical bacterial extrusion?

32. Romualdo PC, de Oliveira KM, Nemezio MA, Küchler EC, Silva RA, Nelson-Filho P, et al. Does apical negative pressure prevent the apical extrusion of debris and irrigant compared with conventional irrigation? A systematic review and meta-analysis. Aust Endod J. 2017 Dec;43(3):129-37. https://doi.org/10.1111/aej.12162

33. Teixeira JM, Cunha FM, Jesus RO, Silva EJ, Fidel SR, Sassone LM. Influence of working length and apical preparation size on apical bacterial extrusion during reciprocating instrumentation. Int Endod J. 2015 Jul;48(7):648-53. https://doi.org/10.1111/iej.12357

34. Kleier DJ, Averbach RE, Mehdipour O. The sodium hypochlorite accident: experience of diplomates of the American Board of Endodontics. J Endod. 2008 Nov;34(11):1346-50. https://doi.org/10.1016/i.joen.2008.07.021

35. Elmsallati EA, Wadachi R, Suda H. Extrusion of debris after use of rotary nickel-titanium files with different pitch: a pilot study. Aust Endod J. 2009 Aug;35(2):65-9. https://doi.org/10.1111/j.1747-4477.2008.00128.x 